\title{
Human Serum Albumin Induced Anaphylaxis in a Patient With Good Tolerance to Human Plasma
}

Moreno Lozano L, Galindo Bonilla P, Borja Segade J, Extremera Ortega A, Gómez Torrijos E, García Rodríguez R Hospital General Universitario de Ciudad Real, Ciudad Real, Spain

J Investig Allergol Clin Immunol 2019; Vol. 29(1): 51-53 doi: $10.18176 /$ jiaci. 0325

Key words: Anaphylaxis. Human serum albumin. Human plasma. Basophil activation test. Immunoblotting.

Palabras clave: Anafilaxia. Albumina humana en suero. Plasma humano. Prueba de activación de basófilos. Inmunoblot.

Human serum albumin (HSA), a 67-kDa protein, accounts for $60 \%$ of the proteins in human plasma. It helps to maintain oncotic pressure and transport hormones and medications. HSA is used as substitution therapy in hypoproteinemia and as a vehicle in some vaccines.

Commercial HSA is obtained from human plasma using the Cohn method, with sterilization by pasteurization at about $60^{\circ} \mathrm{C}$ for 10 hours [1]. The procedure causes albumin to aggregate in polymers, thus creating macromolecules that may be antigenic.

A 51-year-old man with no previous history of drug allergy was diagnosed with metastatic colon adenocarcinoma. He was admitted for partial hepatectomy and received 3 platelet concentrates during the surgical intervention. Four days later, he received intravenous human albumin (Grifols SA). Immediately after an infusion of about $20 \mathrm{~mL}$ of this solution, he developed palmar and lingual pruritus and generalized erythematous-papular exanthema. Oxygen saturation was $93 \%$, although he did not complain of dyspnea. He was treated with oxygen therapy, corticosteroids, and antihistamines and recovered in about 20 minutes. This was his first treatment with intravenous albumin in our hospital, although the patient had previously been treated in another hospital, where he underwent other surgical procedures (appendectomy and ventral midline hernioplasty).

Twelve hours after the reaction, serum tryptase was within normal values $(2.61 \mu \mathrm{g} / \mathrm{L})$. Unfortunately, no blood sample was obtained before that time.

Specific IgE to animal albumins (bovine seralbumin, ovalbumin, pig seralbumin, and $\alpha$-lactalbumin) and skin prick tests (SPTs) with latex, lactalbumin, ovalbumin, and meats (chicken, pork, and veal) all yielded negative results.

SPTs and intradermal tests (IDTs) with purified human albumin (Grifols, CLS Behring, and Roxall Group) were positive at a 1/10 dilution for the Grifols and Roxall products and a 1/100 dilution for the Behring product.

SPTs and IDTs were subsequently performed with the 3 albumins in 5 healthy controls and yielded negative results. Basophil activation tests (BATs) with pure and 1/10 diluted 


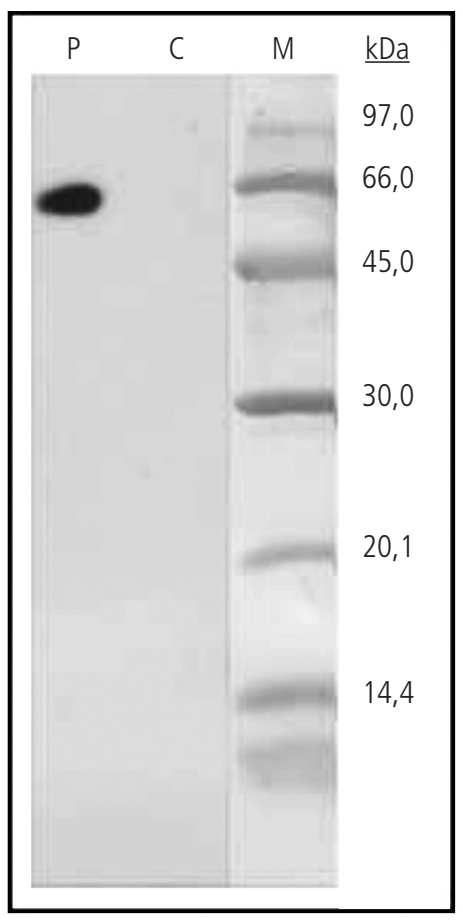

Figure. SDS-PAGE Immunoblotting, human serum albumin. Lane $P$, patient's serum; lane C, control; lane M, molecular weight.

Grifols and Roxall albumin were all positive, showing a degranulation rate of $48 \%$ (control 1\%). Immunoblotting based on the Laemmli SDS-PAGE method performed under reducing conditions with 2-mercaptoethanol showed a $67-\mathrm{kDa}$ band that fixed IgE and corresponded to HSA (Figure).

The positive SPT, BAT, and immunoblotting test results confirmed the presence of sensitization to HSA and suggested a diagnosis of moderate anaphylaxis due to IgE-mediated hypersensitivity to HSA.

This diagnosis requires the patient to avoid intravenous albumin and probably also blood derivatives that contain it, such as plasma or transfusions of red blood cells or platelets. The patient's clinical situation worsened in the following months, making it necessary to transfuse packed red blood cells. He received washed red blood cell concentrates in order to avoid the presence of albumin as much as possible and tolerated the transfusions. However, as he needed more blood or platelet transfusions, the allergy work-up was extended with SPTs and IDTs (1/10) using human plasma, which yielded negative results. A subsequent intravenous challenge with human plasma revealed good tolerance. The patient later received red cell transfusions, which were also tolerated.

We report the case of a patient with a probable IgEmediated hypersensitivity reaction to HSA and good tolerance to human plasma and other blood derivatives.

Hypersensitivity reactions to blood components are common [2], although, to date, the reactions described with human proteins [3] have generally occurred in patients with these protein deficiencies. Cases of hypersensitivity reactions caused by fibrinogen have been reported in patients with congenital or acquired deficiency of this protein [4], as have cases of anaphylaxis induced by the administration of platelet concentrate in patients with congenital haptoglobin deficiency [5] and adverse reactions due to intravenous immunoglobulins in patients with hypogammaglobulinemia [6].

In 1988, Stafford et al [7] reported the first case of allergy to human albumin. The patient was a 20 -year-old pregnant woman who experienced pruritus, urticaria, rash, and tachycardia during the administration of HSA as an adjuvant treatment to prevent $\mathrm{Rh}$ incompatibility. The authors demonstrated an IgE-mediated hypersensitivity reaction to HSA by positive results in IDT and enzyme-linked immunosorbent assay [7]. Nanonechna and Abuzakouk [8] reported a case of bee venom immunotherapy where anaphylaxis was induced after 3 years of therapy. SPT results were positive with the solvent, which contained albumin, thus demonstrating that this protein was responsible for the reaction. Desensitization was achieved in a case of albumin hypersensitivity. However, since the only available data were reported at a pharmacy congress, further details are lacking [9]. The protein that fixed IgE — whether a monomer or, as might be expected, a polymer of albumin — was not identified in any of these cases.

This is the first time that the antigen responsible for the reaction has been shown to be a monomer of albumin using immunoblotting, although the patient may have been sensitized through a polymer or through a modified albumin formed during the procedure to obtain albumin from plasma. This procedure may create macromolecules [10] or structural changes in the albumin molecule that are sufficient for it to be recognized as a foreign molecule that is capable of inducing sensitization. The fact that the patient tolerated plasma and blood derivatives supports the idea that only the albumin that was treated and pasteurized to obtain commercial albumin triggered the reaction.

In conclusion, we report a case of IgE-mediated hypersensitivity to HSA confirmed by skin tests, BAT, and immunoblotting, with good tolerance to plasma and blood derivatives. This is the first case in which the responsible allergen is an albumin monomer. Early diagnosis is highly desirable, because patients would need to be aware of the presence of albumin in diluents and to avoid intravenous albumin, although they could be treated with plasma or blood derivatives. In any case, previous controlled challenge is recommended.

\section{Acknowledgments}

We wish to thank Roxall Laboratories for their contribution to the in vitro study.

\section{Funding}

The authors declare that no funding was received for the present study.

\section{Conflicts of Interest}

The authors declare that they have no conflicts of interest. 


\section{References}

1. Basu D, Kullkarni R. Overview of blood components and their preparation. Indian J Anaesth. 2014;58:529-37.

2. Mertes PM, Bazin A, Alla F, Bienvenu J, Caldani C, Lamy B, et al. Hypersensitivity reactions to blood components: document issued by the allergy committee of the French medicines and healthcare products regulatory agency. J Investig Allergol Clin Immunol. 2011;21:171-8

3. Ring J, Messmer K. Incidence and severity of anaphylactoid reactions to colloid volume substitutes. Lancet. 1977;1:466-9.

4. Solomon C, Gröner A, Ye J, Pendrak I, Solomon C, Gröner $A$, et al. Safety of fibrinogen concentrate: analysis of more than 27 years pharmacovigilance data. Thromb Haemost 2015;113:759-71.

5. Ando J, Masuda A, Lizuka K, Ochiai T, Takaku T, Osawa T, et al. Congenital haptoglobin deficiency discovered on the occasion of anaphylaxis induced by platelet concentrate transfusion. 2016:57:1507-2511.

6. Williams SJ, Gupta S. Anaphylaxis to IVIG Arch. Immunol. Ther. Exp. 2017;65:11-9.

7. Stafford CT, Lobel SA, Fruge BC, Moffitt JE, Hoff RG, Fadel HE. Anaphylaxis to human serum albumin. Ann Allergy. 1988;61:85-8.

8. Nakonechna A, Abuzakouk M. Human albumin causes anaphylaxis during bee venom immunotherapy. Ann Allergy Asthma Immunol. 2014;112:559-60.

9. Villanueva Bueno C, Poyatos Ruiz LL, Santana Pareja V, Montecatine Alonso E, Sierra Torres MI, Santos Rubio MD. Albumin desensitization. Eur J Hosp Pharm. 2015;22 (Suppl 1):A134.

10. Ring J, Stephan W, Brendel W. Anaphylactoid reactions to infusions of plasma protein and human serum albumin. Role of aggregated proteins and of stabilizers added during production. Clin Allergy. 1979;9:89-97.

Manuscript received June 10, 2018; accepted for publication September 17, 2018

Rosa García Rodríguez

Pasaje de Lanzarote $n^{\circ} 4$; portal 2; $3^{\circ} \mathrm{A}$

13001 Ciudad Real, Spain 